\title{
Effect of lactation on the decline of brush border lactase activity in neonatal pigs
}

\author{
D Kelly, T P King, M McFadyen, A J Travis
}

\begin{abstract}
It has been shown that during the early phase of lactation porcine milk contains high concentrations of hormones and growth factors. The aim of the present investigation was to examine the hypothesis that the temporal coordination of intestinal maturation in piglets can be extrinsically regulated through changes in the composition of milk during the suckling.period. Gut morphology and the ontogeny of brush border
\end{abstract} lactase activity were investigated in piglets reared on two suckling regimens designed to expose the animals to compositionally distinct milk. The first group of animals were crossfostered onto postcolostrum sows and thereafter suckled normally for up to eight weeks. These normally suckled $(\mathbf{N})$ animals consequently received both early and late lactation products. The second group of piglets were cross-fostered each week, for up to eight weeks, onto newly farrowed sows which were postcolostrum. As a result of this repeated cross-fostering (CF) these animals received only early lactation products. Animals were sacrificed at one, three, five, seven, and eight weeks postpartum. Biochemically active lactase decreased significantly $(p<0.001)$ in both groups over eight weeks, but the rate of loss of activity was greater in the CF animals than in the $\mathrm{N}$ pigs by approximately $50 \%$ at week 3 and $25 \%$ at week 8. Quantitative histochemical analysis of lactase activity corroborated the biochemical data. At three weeks maximal enzyme activity was observed approximately $400 \mu \mathrm{m}$ from the villus/crypt junction. Histochemically detected lactase decreased throughout the suckling period, but the intensity of reaction product was consistently weaker over the entire villus surface in the $\mathbf{C F}$ animals. Immunocytochemically detectable lactase was identified at the same sites as the histochemical reaction products. In addition, immunofluorescence microscopy showed the presence of histochemically undetectable enzyme on the basolateral and brush border membranes of both villus and crypt cells. Villus/crypt ratios were significantly lower $(\mathbf{p}<0.001)$ in the CF animals than in the $\mathbf{N}$ pigs between weeks 3 and 5 . The results of this study suggest that lactation products can accelerate the loss of brush border lactase activity. The observed decline in biochemically and histochemically detected lactase was considered to be a consequence of reduced enterocyte lifespan, decreased synthesis of enzyme protein, or altered posttranslational modification of enzyme protein, or a combination of these.
The loss of intestinal lactase activity associated with weaning is a well recognised phenomenon. Several hypotheses have been proposed to account for loss of lactase activity and these include gene regulated suppression of the rate of enzyme synthesis, ${ }^{12}$ cytokinetic changes which reduce enterocyte lifespan, ${ }^{3}$ and a two stage decline entailing both the above processes. ${ }^{4}$ Posttranslational events including glycosylation and protein catabolism may also have a role.

It has been shown that prolonged lactation delays but does not prevent the normal lactase loss. ${ }^{6}$ This suggests that although the changes in intestinal lactase activity may occur through a series of programmed cellular events (intrinsic cellular control) the temporal coordination of these programmed processes can be modulated by extrinsic factor. ${ }^{5}$ Current published papers, based predominantly on studies on the rat and mouse, have implicated glucocorticoids and thyroxine as principal hormonal regulators of lactase decline in suckling animals. ${ }^{7-9}$ The exact molecular mechanisms concerned in the repression of lactase activity are still unknown, however.

Mammary secretions are known to contain high concentrations of hormones and growth factors and these may have functional roles in mammary gland development and in neonatal intestinal differentiation. Experiments using several different cultured cell lines have shown that milk stimulates both protein and DNA syntheses. ${ }^{10-12}$ Furthermore, hormones delivered through milk or orally administered have been shown to be absorbed and to be biologically active in influencing differentiation of the small intestine. ${ }^{13-15}$

Compositional changes in growth factors have been reported during lactation in both human and porcine milk. ${ }^{10.1216}$ Maximal mitogenic activity was observed during the first weeks of lactation and progressively declined thereafter. These changes were considered to be physiologically relevant in modulating the temporal maturation of the small intestine. In the present investigation a cross-fostering protocol was adopted as a method of restricting pigs to early milk and, with reference to normally suckled littermates, to show the influence of variation in milk composition on the ontogenic decline of lactase activity in the small intestine.

\section{Methods}

COLOSTRUM COLLECTION

Lactating sows received a single injection of oxytocin to stimulate milk let-down. Colostrum and milk samples were obtained by manual 

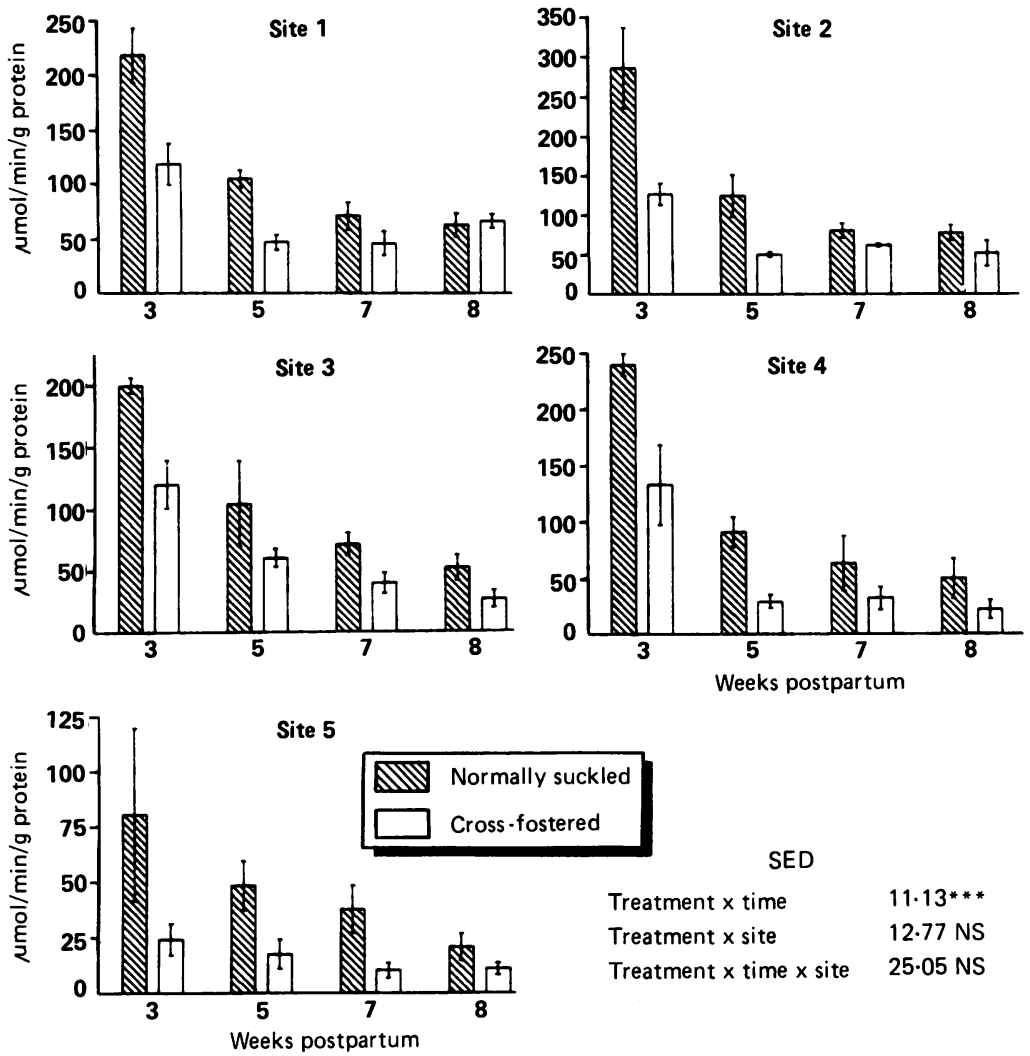

Figure 1: Site specific biochemical lactase activity ( $\mu \mathrm{mol} / \mathrm{min} / \mathrm{g}$ protein) (mean (SEM)) of groups of four cross-fostered and four normally suckled pigs sampled at weeks 3, 5, 7, and 8 postpartum. SED =standard error of the difference between the treatment group means expressed for treatment $\times$ time, treatment $\times$ site, treatment $\times$ time $\times$ site interactions. $\star \star \star p<0.001, N S=$ not significant. during her feeding periods and any spilled food was removed. To maintain hygiene the crates were cleaned and disinfected twice daily. One animal from each of the four litters was killed at week 1 ; thereafter a similar group of four nonlittermates from both the $\mathrm{N}$ and $\mathrm{CF}$ groups was killed at weeks three, five, seven, and eight postpartum.

\section{POSTMORTEM PROCEDURE}

Piglets were removed from the sow two hours before slaughter. Anaesthesia was induced using halothane/oxygen inhalation. A midline laparotomy was performed to expose the intestines. The stomach and the large intestine were sealed with crocodile clips at the pyloric sphincter and the ileocaecal valve respectively. Divisions were made at distances of $10,30,50,70$, and $90 \%$ from the pylorus to the ileocaecal valve, sites 1 to 5 respectively. Lengths of small intestine of 10 $\mathrm{cm}$ were taken at sites 1 to 5 , opened along the mesentery, rinsed with $0.14 \mathrm{M} \mathrm{KCl}$, frozen immediately in liquid nitrogen, and stored at $-20^{\circ} \mathrm{C}$ before analyses. For histochemical analyses intestinal samples were frozen in isopentane cooled in liquid nitrogen. Samples for histology were placed in $4 \%$ formaldehyde with $0 \cdot 2 \mathrm{M}$ phosphate buffer at $\mathrm{pH} 7 \cdot 2$. Samples of intestine were also taken for dry matter determination. Animals were killed by intracardiac injection of pentobarbitone.

\section{ANALYSES}

expression and stored frozen in sterile containers. On the initial day of the experimental trial the colostrum was thawed, pooled, and maintained in a refrigerated tank with gentle agitation to ensure homogeneity.

\section{EXPERIMENTAL ANIMALS}

The progeny for this trial were derived from four sows (Large White $\times$ Landrace). Using a combination of concurrent matings and pharmacological manipulations all sows were farrowed within the same 24 hour period. Nine piglets from each sow were caught at birth and housed in sterile incubators (temperature $34^{\circ} \mathrm{C}$, relative humidity 50\%) for the first 36 hours of life. Each piglet was gavaged with approximately $40 \mathrm{ml}$ of standard colostrum every three hours for 36 hours postpartum. Littermates were then allocated equally to one of two treatment groups. The first group of 18 animals was cross-fostered onto postcolostrum sows (at the same lactation stage as the natural mothers) and thereafter normally suckled for up to eight weeks on the same dams. These normally suckled animals (N) consequently received both early and late lactation products. The second group of 18 piglets were cross-fostered each week, for up to eight weeks, onto newly farrowed sows which were postcolostrum. As a result of this repeated crossfostering (CF) these piglets received only early lactation products. All animals were held in farrowing crates $(2.3 \times 1.7 \times 0.6 \mathrm{~m})$ for the duration of the experiment. To avoid solid feed consumption piglets were removed from the sow

\section{Biochemical analyses}

Preparation of mucosal extracts, dilutions, and methods for determination of lactase ( $\beta$ galactosidase, EC 3.2.1.23) were as described by Kelly et al. ${ }^{17}$ In brief, the mucosa was removed from partially thawed $10 \mathrm{~cm}$ lengths of small intestine and homogenised in $50 \mathrm{ml}$ distilled water. After centrifugation the supernatant was recovered and a twofold dilution was prepared for analysis. The substrate concentrations and the incubation conditions were as described by Kidder and Manners. ${ }^{18} 4$ Chloromercuribenzoate was added to inhibit non-brush border lactase. Protein, RNA, and DNA were determined using the methods described by Bradford, ${ }^{19}$ Sneider, ${ }^{20}$ and Greer et al. ${ }^{21}$ Cortisol determinations were carried out at week 3 on blood samples taken from both treatment groups at a time when the $\mathrm{CF}$ animals were within 24 hours of having been transferred to a new foster mother. Plasma samples were extracted with ethanol ${ }^{22}$ and a modified radioimmunoassay ${ }^{23}$ performed using antiserum supplied by ICN Biomedicals (High Wycombe, Bucks)

\section{Histology}

Samples of small intestine stored in 4\% formaldehyde in $0.2 \mathrm{M}$ phosphate buffer were cut into blocks $(10 \mathrm{~mm} \times 5 \mathrm{~mm})$, washed in phosphate buffer, dehydrated in an ethanol series, and embedded in LKB historesin. Sections $(1-2 \mu \mathrm{m})$ were cut on a Reichert 'autocut' microtome using a glass knife. Sections were dried onto ethanol- 

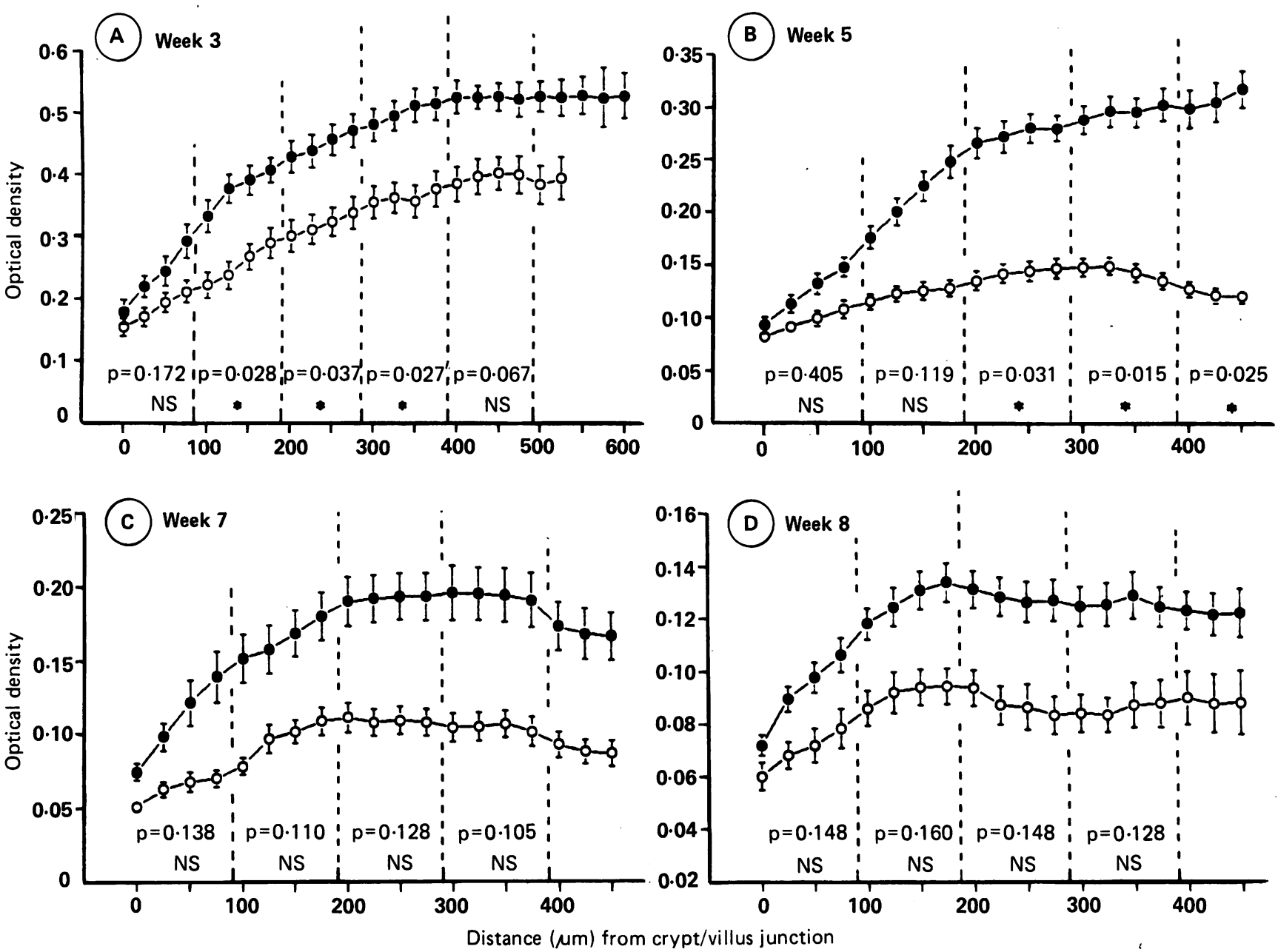

Figure 2: Quantitative histochemistry of brush border lactase at intestinal site 3 in groups of four cross-fostered (open circles) and four normally suckled (closed circles) pigs sampled at weeks 3, 5, 7, and 8 weeks postpartum (A-D respectively). For statistical analysis the data were separately assessed for each of four or five defined regions on the villus axis as shown. The 'within pairs' errors were pooled for weeks 3, 5, 7, and 8 to give a single 'within pairs error' for each region which was used to calculate the standard error of the difference $(S E D)$ between the two treatment group means. ${ }^{\star} p<0.05$, NS =not significant. The error bars shown on plotted points are unrelated to the main statistical analyses and indicate the SEM of the 30-40 observations at each of the $25 \mu \mathrm{m}$ intervals.

cleaned uncoated microscope slides using a hot plate. Sections from sites 1,3 , and 5 of the small intestine were stained with haematoxylin and eosin and measurements of villus height and crypt depth made from approximately 20-30 well orientated villi.

\section{Histochemistry}

Cryostat sections $(6 \mu \mathrm{m})$ of site 3 (jejunal) intestinal samples were used for cytochemical determination of lactase activity using 4-chloro-5-bromo-3-indolyl- $\beta$-D-fucoside. ${ }^{24}$

Optical density measurements of enzyme reaction products on the tissue sections were made using a Torch QuadX Image processing workstation (Torch Technology, Cambridge, UK). The QuadX system consists of a 68020 based Unix workstation with $4 \mathrm{Mb}$ RAM and $80 \mathrm{Mb}$ Winchester disk, and a Primagraphics Virtuoso 8-bit video frame store. This system was used to capture images and measure optical density at resolution of 256 grey-levels from a Sony AVCD5CECCD monochrome video camera fitted to the camera port of the microscope. The performance of the system was assessed using photographic neutral density filters of known optical density (B+W, Germany).

Images were processed using VCS (Vision Dynamics, Hemel Hempstead, UK). The VCS software (Vision Control System) provides an interactive interpreter for the VCS command language. The VCS interpreter was used to implement a systematic sampling strategy based on the rectangular grid superimposed on the image. The sampling grid was calibrated to provide measurements of $25 \mu \mathrm{m}$ intervals, positioned automatically over a freehand line drawn along the villus brush border. Optical density measurements were made at the points of intersection between the sampling grid and the drawn brush border line, with reference to the average grey level of a sample of crypt brush border adjacent to the region of interest. Quantitative histochemistry was undertaken on jejunal samples from both $\mathrm{N}$ and $\mathrm{CF}$ animals taken at weeks 3, 5, 7, and 8 postpartum. For each treatment/time point at least three replicate histochemical incubations were undertaken and on each occasion optical density measurements were made on both sides of at least five villi. The data were collated and presented as a villus histochemical profile.

\section{Immunocytochemistry}

Indirect immunofluorescence labelling was performed on $6 \mu \mathrm{m}$ cryostat tissue sections. The mouse monoclonal antiporcine lactase antibody (Mab PBB3/7/3/2) was obtained from Professor B 
Figure 3: Histochemical and immunocytochemical localisation of lactase at site 3 in cross-fostered (CF) and normally suckled $(N)$ pigs at three weeks postpartum. (A) Histochemical determination of lactase in $N$ pig and $(B)$ in $C F$ pig. (C) Immunocytochemical localisation of lactase in $N$ pig and $(D)$ in $C F$ pig. $(E)$ Immunocytochemical localisation of lactase on brush border $(B B)$ and basolateral membranes (BLM) of crypt cells of $C F$ pig and $(F)$ of villus cells of $C F$ pig.
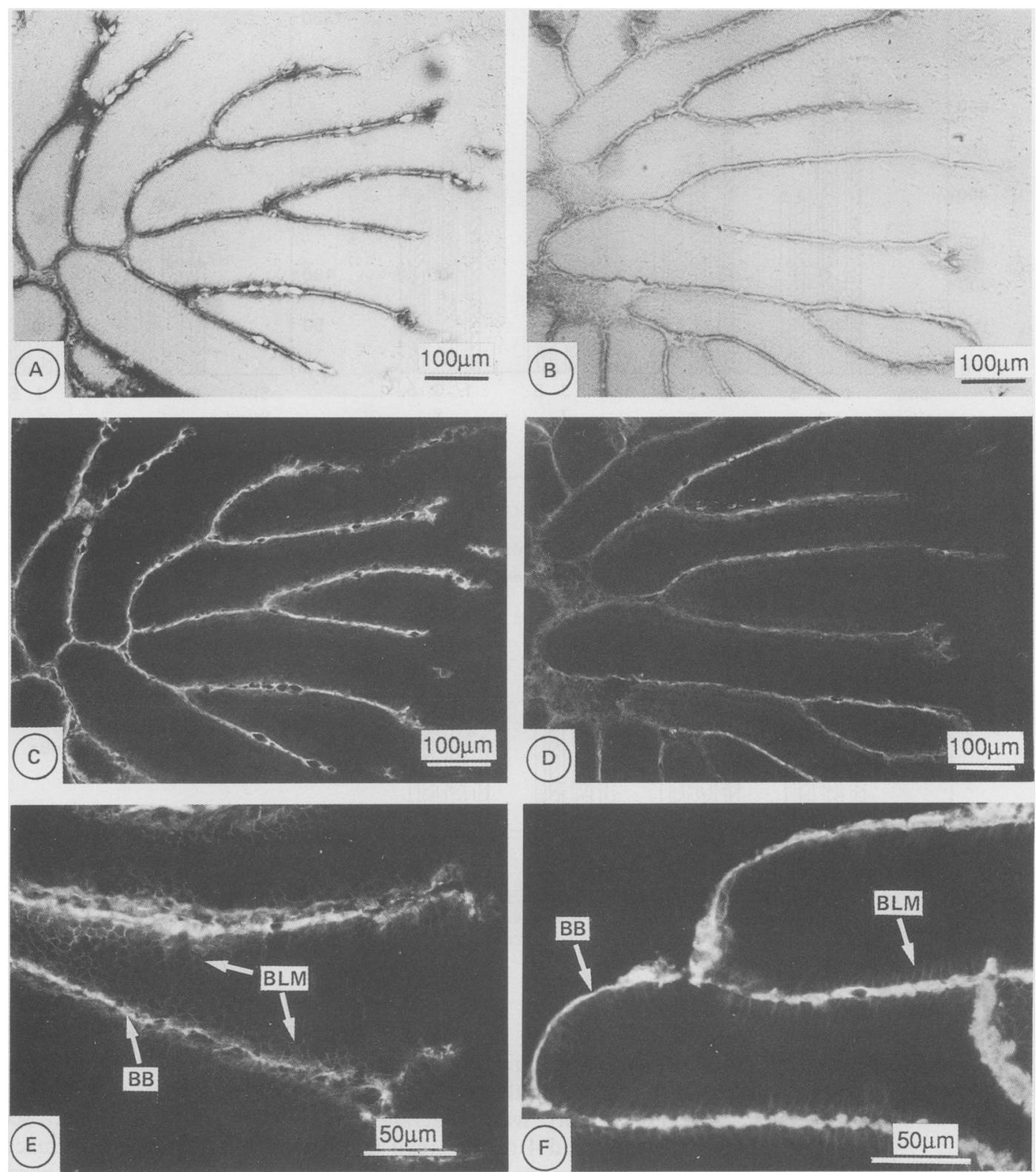

L Nichols, Children's Nutrition Research Centre at Baylor College of Medicine, Houston, Texas. Fluorescein isothiocyanate (FITC)-labelled antimouse IgG was an affinity isolated antibody purchased from Sigma (Poole, Dorset, UK). Optimal dilutions of the antibodies were determined by checkerboard titration. Sections were covered by $200 \mu \mathrm{l}$ of Mab diluted in phosphate buffered saline and incubated for one hour. After an intermediate wash in phosphate buffered saline the sections were incubated for one hour in the second antibody (FITC-mouse IgG). After washing in phosphate buffered saline the sections were mounted in citifluor antifadent mounting solution (Agar Scientific, Stansted, Essex, UK) and examined with a Leitz Ortholux II microscope equipped with a Ploemopak illuminator and a light source of 50 watts. Results were photographed with a Leitz Orthomat $35 \mathrm{~mm}$ automatic camera using Kodak Pan X or Ectachrome 100 ASA film. Controls consisted of substituting phosphate buffered saline or mouse ascites fluid $(10 \mu \mathrm{g} / \mathrm{ml})$ for the primary monoclonal antibody.
STATISTICAL ANALYSIS

The data obtained from this study were subjected to an analysis of variance using the genstat package. The values obtained for week 1 animals were incorporated as covariates in the analysis.

\section{Results}

The average weight gains of the two treatment groups were comparable at week $3(3.66 \mathrm{~kg}$ and $3.70 \mathrm{~kg}$ for $\mathrm{CF}$ and $\mathrm{N}$ pigs respectively). By the last week of the experiment, however, the weights were $10.3 \mathrm{~kg}$ and $11.5 \mathrm{~kg}$ in the CF and $\mathrm{N}$ groups respectively. This weight difference was significant $(p<0.05)$. The mean $(S E M)$ plasma cortisol concentrations at the time of sampling were $92.49(11.94) \mathrm{ng} / \mathrm{ml}$ and 90.27 $(11.08) \mathrm{ng} / \mathrm{ml}$ for the $\mathrm{CF}$ and $\mathrm{N}$ groups respectively.

At week 1 the mean (SEM) lactase activity (over five intestinal sites from the four nonlittermates) was $376(27) \mu \mathrm{mol} / \mathrm{min} / \mathrm{g}$ protein. There was a significant $(p<0.001)$ decline in the biochemical activity of lactase during the experi- 

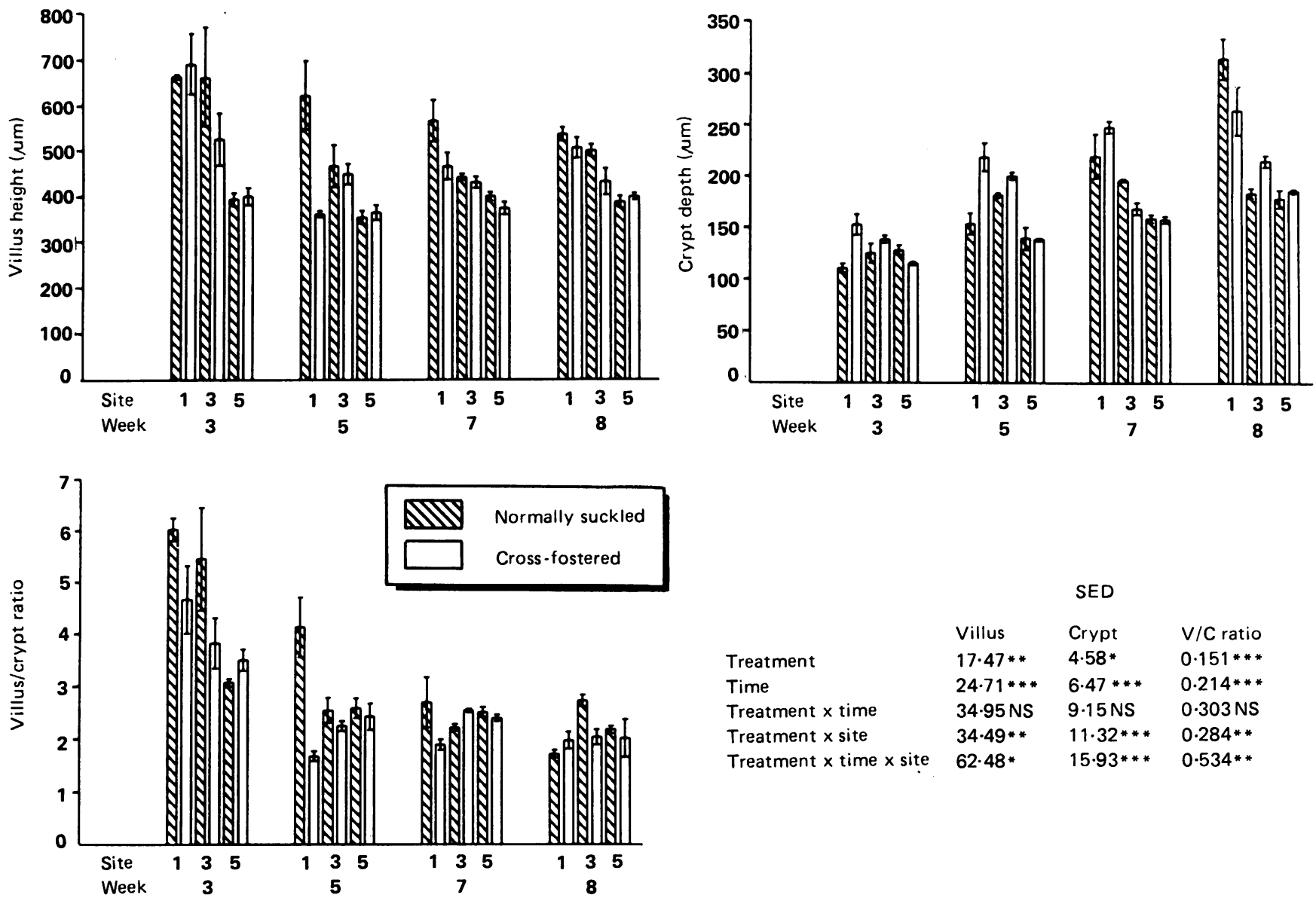

Figure 4: Site specific villus and crypt measurements (mean (SEM) at sites 1,3, and 5) of groups of four cross-fostered and four normally suckled pigs sampled at weeks $3,5,7$, and 8 postpartum. SED =standard error of the difference between the two treatment group means expressed for treatment, time, and treatment $\times$ time, treatment $\times$ site, treatment $\times$ time $\times$ site interactions. $\star \star \star p<0 \cdot 001, \star \star p<0.01, \star_{p}<0.05, N S=$ not significant.

mental period in both treatment groups. The initial rate of loss of activity, however, was more rapid in the $\mathrm{CF}$ group than in the $\mathrm{N}$ group (Fig 1). Lactase activity was moderately uniform between sites 1 and 4 of the small intestine in both treatment groups, although there was a trend for activity to peak at site 2 . Activity was significantly lower at site 5 compared to the more proximal intestinal sites. Lactase activity was consistently higher at all sites along the small intestine in $\mathrm{N}$ animals compared to $\mathrm{CF}$ animals. There were no significant treatment $\times$ site or treatment $\times$ time $\times$ site interactions.

Histochemical analysis of lactase activity at site 3 corroborated the findings of the biochemical data. At three weeks lactase activity increased linearly along the villus axis, attaining maximal values at approximately $400 \mu \mathrm{m}$ from the villus/ crypt junction in both treatment groups (Fig 2A). By five weeks overall activity had decreased in both groups. In the $\mathbf{N}$ group the enterocytes continued to show increased activity during migration from the crypt and along the lower to mid-regions of the villus. This is in contrast to the CF animals in which the activity was much lower and uniformly distributed (Fig 2B). At seven and eight weeks the lactase activity was further diminished in both groups (Fig 2C and D).

At week 1 histochemically demonstrable lactase was high in intestinal samples from both CF and $\mathrm{N}$ pigs. As indicated, however, by week 3 a precocious decline in lactase activity was evident in the $\mathrm{CF}$ group (Fig $3 \mathrm{~A}$ and $\mathrm{B}$ ). Immuno- cytochemically detectable lactase protein was identified at the same sites as the histochemical reaction products (Fig $3 \mathrm{C}$ and D). The immunofluorescence microscopy, in addition, showed histochemically inactive enzyme on the basolateral and brush border membranes of crypt and villus cells (Fig $3 E$ and F). In keeping with the biochemical and histochemical data a progressive decline in the expression of both crypt and villus lactase occurred throughout the lactation period. This decline was more rapid and conspicuous in the CF group.

There was a trend towards a reduction in villus height over the eight week suckling period (Fig 4). The villus height averaged over all intestinal sites and over all time points was significantly $(\mathrm{p}<0.01)$ greater in $\mathrm{N}$ pigs than in the CF pigs. There was a particular loss of villus height at site 1 between three and five weeks in pigs on the CF treatment, giving rise to a significant $(p<0.05)$ interaction between treatment, time, and site. Crypt depth significantly $(\mathrm{p}<0.001)$ increased with time in both treatment groups. Crypts at site 1 were longer in CF animals than in $\mathrm{N}$ animals at weeks 3,5 , and 7 . At eight weeks, however, this trend was reversed, resulting in a highly signifcant $(p<0.001)$ treatment $\times$ time $\times$ site interaction. The overall effect of treatment on the villus/crypt ratio was highly significant $(\mathrm{p}<0.001)$. Villus/crypt ratios were greater at sites 1 and 3 in $N$ pigs than in CF pigs at weeks 3 and 5 and again resulted in a significant $(p<0.01)$ treatment $\times$ time $\times$ site interaction. 


\section{Discussion}

The ontogenic decline in intestinal lactase activity seems to be intrinsically programmed, a view substantiated by data derived from studies using intestinal isografts and transplants ${ }^{25}{ }^{26}$ and from bypassed intestinal segments. ${ }^{27}$ It is recognised, however, that extrinsic humoral and luminal factors can also modulate the differentiation processes of the intestine and these have been extensively reviewed by Henning. ' The results of the current study suggest that factors supplied in milk can specifically regulate the decline in brush border lactase in the neonatal pig.

Cross-fostering animals onto newly farrowed sows resulted in an enhanced loss of brush border lactase activity during the postnatal period compared with that observed in normally suckled littermates. Although the cross-fostering procedure could be considered potentially stressful, neither piglets nor sows seemed to display adverse behavioural traits. Weight gain, and by inference food intake, were comparable in both treatment groups during the early weeks of the experiment when stress effects were likely to have been maximal. Serum concentrations of cortisol and corticosterone have been shown to be raised in stressful situations ${ }^{28}$ but no differences were observed between treatment groups in this study nor were the values unduly high. Furthermore, glucocorticoids are known to induce the precocious appearance of sucrase and maltase enzymes, ${ }^{152}$ but such disaccharidase responses were not demonstrable in the CF animals, ${ }^{30}$ which may have been considered to have been reared under unusual circumstances.

The crucial period with regard to lactase decline in the cross-fostered animals was during the initial three weeks of this study. Approximately $70 \%$ of the activity was lost from the brush borders of these animals between weeks 1 and 3 postpartum. As indicated, during this period weight gains were comparable in both treatment groups. It is therefore unlikely that the precocious decline in lactase in the cross-fostered animals was related to nutrient deprivation. In the latter part of this study, however, although both groups were in positive nutrient balance the cross-fostered animals grew at a slower rate. It could be argued that intake of lactose influenced the rate of lactase decline. The published evidence for substrate induction of lactase is inconclusive and indeed some evidence argues against this phenomenon in the postnatal period. ${ }^{31}$ It is also possible that indirect effects of nutrient intake on energy and metabolic and endocrine functions may have contributed to differences in the lactase activity in the two treatment groups during the latter period of the study. Since the proportional loss of lactase was greatest in the first three weeks in the CF group it is equally plausible that milk utilisation by these animals in the latter part of the experiment was compromised by the lower brush border lactase activity.

The suggestion that growth factors/hormones in maternal secretions may be responsible for the observed effect on lactase expression is further supported by our recent findings that colostrum feeding enhances the rate of loss of lactase activity relative to that in colostrum deprived animals reared under identical conditions and at equivalent feeding levels (unpublished data).

The loss of lactase activity which occurred during the suckling period in both groups of animals was confirmed both biochemically and using quantitative histochemical procedures. From the biochemical data it is apparent that the difference in activity between the two groups was maximal between weeks 3 and 5 and that by eight weeks both groups were approaching basal levels, although the treatment effect was still apparent. Temporally correlated with these biochemical differences were changes in villus/crypt morphology, although a positive correlation between these two effects remains to be proved. Using a quantitative histochemical technique it was possible to determine the changes in lactase activity of enterocytes as they migrated along the villus axis. ${ }^{32}$ At three weeks lactase activity increased linearly in both cross-fostered and normally suckled animals. For the remainder of the experimental period lactase activity was uniformly distributed along the villus axis in the cross-fostered animals. In contrast, at five, seven, and eight weeks lactase activity of enterocytes from the normally suckled animals continued to increase during migration; over this period maximal activity was expressed at decreasing distances from the villus/crypt junction. The decline in lactase activity has previously been attributed to changes in enterocyte lifespan ${ }^{33}$ or to a reduced synthesis of the enzyme protein. ${ }^{1}$ With the information available in the current study it is difficult to reconcile the relative contributions of these two effects. Crypt hyperplasia, however, was more extensive in the cross-fostered pigs than in their normally suckled littermates, particularly between weeks 3 and 5 . This result suggests a faster rate of cell turnover in the cross-fostered group and proportionately more immature cells with reduced enzyme activity occupying the villus column. A positive correlation between the enzyme activity and intestinal morphology is therefore suggested but requires further investigation incorporating cellular kinetic studies.

Postnatal lactase decline was further investigated using semiquantitative immunocytochemical localisation. The immunoreactive form of the enzyme was found in both the crypt and villus regions of the intestinal epithelium in both treatment groups. The intensity of staining decreased with time, implying reduced synthesis of the enzyme protein during the later stages of lactation. What was particularly interesting, though, was the discrepancy between the biochemical or histochemical analyses and the data obtained using antibody localisation. The implication of these results is that during the postnatal period biochemically inactive enzyme protein is produced. This opinion is further substantiated when considered in conjunction with the findings of King and Kelly ${ }^{3+}$ that cross-fostering animals onto early lactation products accelerated the rate of fucosylation of the brush border membrane compared to normally suckled control animals. This finding may be related to recent reports of a high molecular form of lactase $(300 \mathrm{k})$ which 
is highly fucosylated and is biochemically inactive. ${ }^{35} 36$

Mammary secretions are known to contain high concentrations of hormones and growth factors. ${ }^{37}$ It has been shown recently that concentrations of the specific growth factors epidermal growth factor and insulin in porcine and human colostrum and milk are high during the first week of lactation and decline rapidly thereafter. ${ }^{1016}$ Furthermore, the mitogenic activity of porcine milk has been shown to decline during lactation and it has been suggested that these changes may be physiologically relevant to the developing intestine. ${ }^{12}$ Until now investigations of the expression of intestinal lactase activity have tended to concentrate on the laboratory rat and the key regulatory candidates implicated in the ontogenic decline of lactase activity are the glucocorticoid and thyroid hormones, also constituents of mammalian milk. ${ }^{25}$ Although the precise regulatory mechanisms involved in the expression and repression of intestinal lactase in the pig have not been elucidated, the results of the current study suggest that lactation products can significantly influence the rate of decline of this brush border enzyme.

We are grateful to Dr A Quaroni, Cornell University, New York, and Professor B L Nichols, Children's Nutrition Research Centre, Baylor College of Medicine, Houston, for the generous gift of the monoclonal antiporcine lactase antibody. We thank Mrs D Slater for technical assistance with the histochemistry.

1 Jonas MM, Montgomery RK, Grand RJ. Intestinal lactase synthesis during postnatal development in the rat. Pediatr Res 1985; 19: 956-62.

2 Kretchmer N. Memorial Lecture: Lactose and lactase - a historical perspective. Gastroenterology 1971; 61: 805-14.

3 Tsuboi KK, Kwong LK, Neu J, Sunshine P. A proposed mechanism of normal intestinal lactase decline in the postweaned mammal. Biochem Biophys Res Commun 1981; 101:

4 Smith MW, James PS. Cellular origin of lactase decline in postweaned rats. Biochim Biophys Acta 1987; 905: 503-6.

5 Goda T, Quaroni A, Koldovsky L. Characterisation of degradation of sucrase-isomaltase in rat jejunum with monoclonalantibody-based enzyme-linked immunosorbent assay. Biochem $\mathcal{F}$ 1988; 250: 41-6.

6 Lebenthal E, Sunshine P, Kretchmer N. Effect of prolonged nursing on the activity of intestinal lactase in rats. Gastroenterology 1973; 64: 1136-41.

7 Yeh KY, Moog F. Influence of thyroid and adrenal glands on the growth of the intestine of the suckling rat and on the development of intestinal alkaline phosphatase and disaccharidase activities. $\mathcal{F}$ Exp Zool 1977; 200: 337-48.

8 Paul T, Flatz G. Temporary depression of lactase activity by thyroxine in suckling rats. Enzyme 1983: 30: 54-8.

9 Henning SJ. Functional development of the gastrointestinal tract. In: Johnson LR, ed. Physiology of the gastrointestinal tract. 2nd ed. New York: Raven Press, 1987: 285-300.

10 Read, LC, Upton FM, Wallace JC, Dahlenberg GW, Ballard FJ. Changes in the growth promoting activity of human milk during lactation. Pediatr Res 1984; 18: 133-9.

11 Steimer KS, Packard R, Holden D, Klasgsbrun M. Gastrointestinal absorption of epidermal growth factor in suckling rats. Am F Physiol 1984; 246: G80-G90.
12 Cera K, Mahan DC, Simmen FA. In vitro growth-promoting activity of porcine mammary secretions: initial characterization and relationship to known peptide growth factors. f Anim Sci 1987; 65: 1147-57.

13 Revsin B, Lemen RG, Koldovsky O. Fate of prostaglandin E in suckling rats after intragastric administration. Biochim Biophys Acta 1982; 711: 101-6.

14 Thornburg W, Matrisian L, Magun B, Koldovsky O. Gastrointestinal absorption of epidermal growth factor in suckling rats. Am F Physiol 1984; 246: G80-G5

15 James PS, Smith MW, Trivey DR, Wilson TJG. Epiderma growth factor selectively increases maltase and sucrase activities in neonatal piglet intestine. $\mathcal{F}$ Physiol (Lond) 1987 393: 583-94.

16 Jaeger LA, Lamar CH, Bottoms GD, Cline TR. Growth stimulating substances in porcine milk. Am $\mathcal{F}$ Vet Res 1987: 48: 1531-3.

17 Kelly D, Smyth JA, McCracken KJ. Effect of creep feeding on structural and functional changes of the gut of early-weaned structural and functional changes of

18 Kidder DE, Manners MJ. The level and distribution of carbohydrases in the small intestine mucosa of pigs from 3 carbohydrases in the small intestine mucosa of pigs f

19 Bradford $M$. A rapid and sensitive method for the quantitation of microgram quantities of protein utilizing the principle of protein-dye binding. Anal Biochem 1976; 72: 248-54.

20 Sneider WC. Determination of nucleic acids in tissues by pentose analysis. Methods Enzymol 1957; 3: 680-4.

21 Greer F, Brewer AC, Pusztai A. Effect of kidney bean (Phaseolus vulgaris) toxin on tissue weight and composition and some metabolic functions in rats. BrF Nutr 1985; 54: 95103.

22 Vecsei P, Penke B, Katzy R, Baek L. Radioimmunological determination of plasma cortisol. Experientia 1972;28: $1104-5$

23 Ruder HP, Guy RL, Lipsett MB. A radioimmunoassay for cortisol in plasma and urine. $\mathcal{F}$ Clin Endocrinol 1972; 35: 219 24.

24 Lodja Z, Kraml J. Indigogenic methods for glycosidases. III. An improved method with 4-Cl-5-Br-3-indolyl- $\beta$-D-fucoside and its application in studies of enzymes in the intestine kidney and other tissues. Histochemie 1971; 25: 195-207.

25 Kendall K, Jumawan J, Koldovsky O, Krulich L. Effect of the host hormonal status on development of sucrase and acid $\beta$ (6. galactosidase in is

26 Montgomery RK, Sybicki MA, Grand RK. Autonomous biochemical and morphological differentiation in fetal rat intestine translated at 17 and 20 days of gestation. Dev Biol 1981; 87: 76-84.

27 Tsuboi KK, Kwong LK, Ford WDA, Colby T, Sunshine P. Delayed ontogenic development in the bypassed ileum of the infant rat. Gastroenterology 1981; 80: 1550-6.

28 Worsaae $\mathbf{H}$, Schmidt M. Plasma cortisol and behaviour in early-weaned pigs. Acta Vet Scand 1980; 21: 640-57.

29 Henning SJ. Post-natal development: coordination of feeding digestion and metabolism. Am f Physiol 1981; 241: G199G214.

30 Kelly D, King TP, McFadyen M. Lactation products on brush border enzyme expression in pigs from 1-8 weeks of age. Proc Nutr Soc 1990; 49: 141A.

31 Goda T, Koldovsky O. Dietary regulation of small intestinal disaccharidases. World Rev Nutr Diet 1988; 57: 265-329.

32 Lund EK, Bruce MG, Smith MW, Ferguson A. Selective effects of graft-versus-host reaction on disaccharidase expression by mouse jejunal enterocytes. Clin Sci 1986; 71: 187-98.

33 Tsuboi KK, Kwong LK, O'Harlingue E, Stevenson DK, Kerner JA, Sunshine $P$. The nature of maturational decline of intestinal lactase activity. Biochim Biophys Acta 1985; 840: 60-78.

34 King TP, Kelly D. Effect of lactation products on the expression of intestinal membrane glycoconjugates in pigs. Proc Nutr Soc 1990; 49: 142A.

35 Nis-Emvo E, Launay JF, Raul F. Is adult-type hypolactasia in the intestine of mammals related to changes in the intracellu-

36 Mantei N, Villa M, Enzler T, et al. Complete primary structure of human and rabbit lactase-phlorizin hydrolase: implications for biosynthesis membrane anchoring and evolution of the enzyme. EMBO F 1988; 7: 2705-13

37 Koldovosky O. Hormones in milk. Life Sci 1980; 26: 1833-6. 